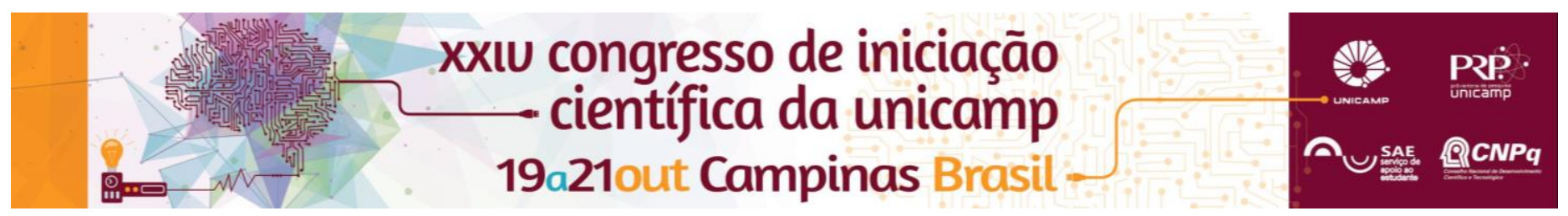

\title{
Efeito tardio da aplicação de células tronco-mesenquimais no reparo de tendão
}

\author{
Luis-F. Rodrigues Teodoro*, André L. Bombeiro, Cristina P. Vicente, Andrea A. Aro, Edson R. Pimentel.
}

\section{Resumo}

Tendões são estruturas cuja principal função é transmitir a força da contração muscular aos ossos. O tendão calcâneo é frequentemente acometido por lesões, vários tratamentos tem sido empregados com o intuito de melhorar as chances de reparo. A terapia celular com o uso de células tronco (CT) tem sido bastante utilizada para o reparo de tecidos. Nesse trabalho utilizamos células tronco mesenquimais e avaliamos os tendões parcialmente transeccionados e submetidos a tal tratamento. $\mathrm{Na}$ análise da quantificação de hidroxiprolina maior concentração foi encontrada no Grupo $\mathrm{N}$ em relação ao apenas transeccionado $(\mathrm{T})(\mathrm{P}<0.01)$. . Nenhuma diferença foi detectada entre o grupo controle $(\mathrm{N})$ e 0 grupo transeccionado e tratado com células tronco $(T+C T)$ e entre $T$ e $T+C T$. A biomecânica demonstrou que maior tensão foi encontrada em $\mathrm{N}$ em relação ao grupo $\mathrm{T}$, porém há uma tendência de ser maior em $T+C T$ do que em $T$. A análise do imageamento in vivo mostrou que 7 dia após a aplicação das CT, não há mais presença dessas células no local da lesão indicando migração ou diferenciação total das células utilizadas.

\section{Palavras-chave}

Tendão, reparo tecidual, terapia celular.

\section{Introdução}

O tratamento de lesões no tendão calcâneo, uma vez lesionado, mesmo após procedimento cirúrgico retorna com deficiências mecânicas que aumentam o risco de uma nova lesão ${ }^{1}$. Nosso trabalho tem focado em uma abordagem que vise o reparo do tendão com o uso de terapia celular, tendo como objetivo melhorar as propriedades mecânicas do tendão lesionado submetido a este tratamento.

\section{Resultados e Discussão}

A quantificação de Ho-Pro (figura 1) mede indiretamente a quantidade de colágeno. Os testes estatísticos mostram uma diferença significativa $(\mathrm{P}<0.05)$ do grupo controle $(\mathrm{N})$ para o lesionado $(\mathrm{T})$ porem não houve diferença entre os demais grupos.

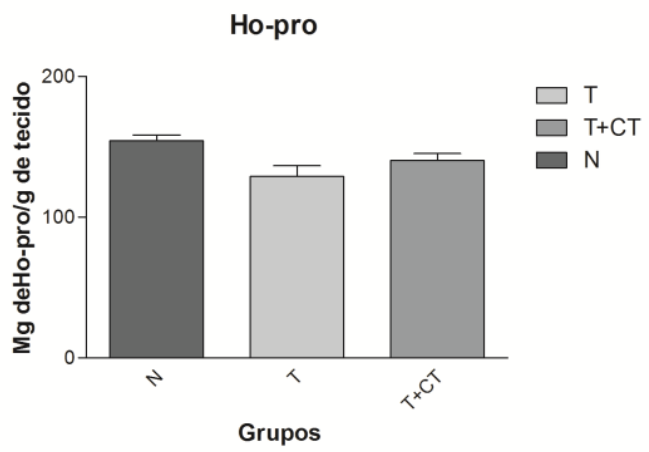

Figura 1: gráfico Ho-pro todos os grupos.

Testes biomecânicos mostraram tensão máxima no grupo $\mathrm{N}$ em relação ao $\mathrm{T}$, mas não entre os demais grupos. Porém ela tende a ser maior no $T+C T$ em relação ao $\mathrm{T}$.

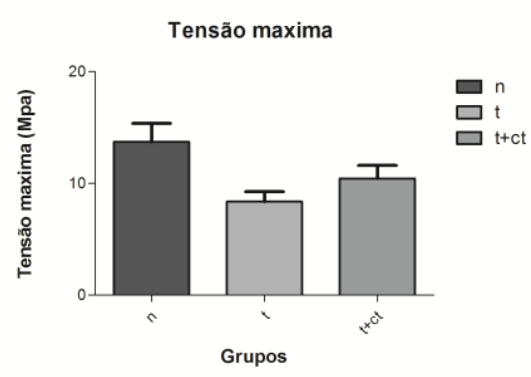

Figura 2: Tensão máxima nos grupos

O imageamento in vivo (figura 3) revelou que após 7 dias não há mais células tronco marcadas no local da lesão.
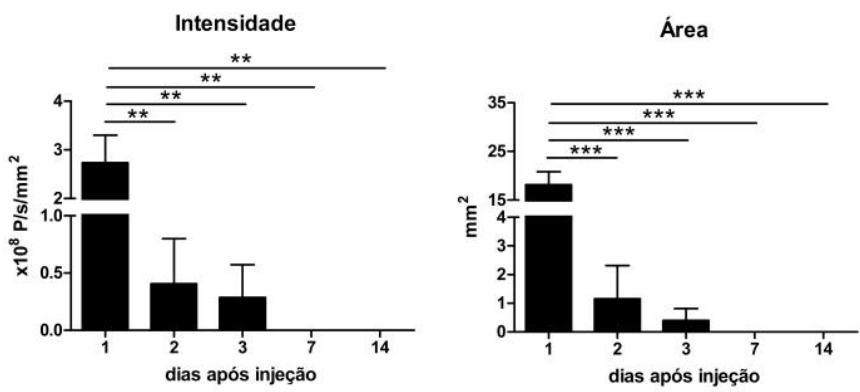

\section{Conclusões}

Apesar de não terem sido observadas diferenças estatísticas entre os grupos, pode-se notar uma tendência de valores maiores tanto para HO-Pro como para valores de Tensão, nos grupos $T+C T$ quando comparados com os grupos apenas lesionados.

\footnotetext{
${ }^{1}$ Sharma P. Maffulli N. J. Bone Joint Surg. Am. 87:187-202, 2005.
} 